\title{
Cientistas em ação: mais tempo e pesquisas são indispensáveis para desvendar o vírus A (H1N1)
}

\author{
Scientists in action: more time and research essential \\ for uncovering the A (H1N1) virus
}

Entrevista com/Interview with Marilda Mendonça Siqueira

Pesquisadora do Laboratório de Vírus Respiratórios e Sarampo/

Fundação Oswaldo Cruz, 4365

21045-900 - Rio de Janeiro - RJ Brasil

mmsiq@ioc.fiocruz.br

Concedida a/Interview given to

Roberta Cardoso

\section{Cerqueira}

Editora executiva de História, Ciências, Saúde - Manguinhos cardosoc@coc.fiocruz.br

\section{Ruth B. Martins}

Jornalista da Casa de Oswaldo Cruz hscience@coc.fiocruz.br
SIQUEIRA, Marilda Mendonça. Cientistas em ação: mais tempo e pesquisas são indispensáveis para desvendar vírus A (H1N1). Entrevista concedida a Roberta Cardoso Cerqueira e Ruth B. Martins. História, Ciências, Saúde - Manguinhos, Rio de Janeiro, v.16, n.4, out.-dez. 2009, p.1057-1063.

\section{Resumo}

Responsável pelo Laboratório de Vírus Respiratórios e Sarampo da Fundação Oswaldo Cruz, Marilda Mendonça Siqueira comenta as estratégias dos órgãos públicos de saúde que conseguiram adiar a entrada do vírus no Brasil, bem como o colapso das redes de atendimento em épocas de crise. Destaca que, no momento inicial da epidemia, o número de contaminados no México e Chile era assustador, o que justificou o alerta máximo como medida de prevenção em nosso país. Explica que o H1N1 é um rearranjo genômico de três espécies diferentes do vírus - aviário, humano e suíno - e que ninguém ainda havia a ele se exposto, daí o alarme quando começaram as contaminações. Comenta também sobre a curiosidade científica em torno do vírus e a necessidade de prosseguir com estudos que vêm sendo realizados.

Palavras-chave: influenza; vírus A (H1N1) pandêmico; gripe suína; rearranjos genômicos; América Latina.

\section{Abstract \\ Marilda Mendonça Siqueira, who is in charge of the Oswaldo Cruz Foundation's Respiratory Viruses and Measles Laboratory, talks about the public health strategies that managed to delay the arrival of the virus in Brazil and about the collapse of healthcare networks during times of crisis. She points out that an alarming number of people fell sick in Mexico and Chile at the outset of the epidemic, which justified adoption of the highest alert level as a preventative measure in Brazil. She explains that H1N1 is a genome rearrangement of three virus species (avian, human, and swine) to which no one had previously been exposed - hence the grave concern when contamination first started. She also comments on scientific curiosity about the virus and the need to move forward with current research into it.}

Keywords: influenza; pandemic A (H1N1) virus; swine flu; genome rearrangement; Latin America. 
$\mathrm{E}$ m 25 de agosto de 2009, quando a gripe A (H1N1) já se propagava em proporções mundiais, recorremos mais uma vez à pesquisadora Marilda Mendonça Siqueira, do Departamento de Virologia da Fundação Oswaldo Cruz (Fiocruz). Fomos ouvi-la como fizemos em janeiro de 2005, quando esclareceu uma série de dúvidas sobre a gripe aviária. Responsável pelo Laboratório de Vírus Respiratórios e Sarampo, ela respondeu a uma bateria de perguntas sobre o A (H1N1), que varreu as Américas Central e do Sul no último inverno e agora é motivo de apreensão nos países do hemisfério norte, onde a estação mais fria está prestes a chegar.

Algumas das repostas da pesquisadora foram esclarecedoras, como por exemplo o porquê de as grávidas estarem entre os grupos de risco e os idosos terem se contaminado menos do que o esperado nessa epidemia. Outras perguntas, como verão os leitores, foram respondidas com novas questões, ainda sem resposta.

Durante toda a entrevista, em sua sala de trabalho no campus de Manguinhos, Marilda Siqueira e uma assistente organizavam formulários com informações sobre numerosos casos suspeitos da gripe no Rio de Janeiro. Eram resultados dos exames de secreções respiratórias encaminhadas para o laboratório da Fiocruz, que integra a rede internacional de vigilância de influenza da Organização Mundial de Saúde (OMS).

Naquela ocasião não se sabia, nem se sabe até agora, como reagirão ao vírus as populações da África e da Europa, por exemplo. A boa nova é que vários países já começaram a aplicar a vacina contra esse vírus específico.

À entrevista!

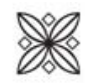

Diante do atual cenário de pandemia da influenza A (H1N1), o que dizer do grau de eficácia e preparo das estruturas de assistência à população fornecidas pelos serviços de saúde?

Marilda M. Siqueira - Sabemos que o sistema de saúde no Brasil, em nível hospitalar, tem muitos problemas. A medicina privada, que atende basicamente a classe média e pessoas que têm condição de pagar, consegue dar um apoio importante quando vivemos situações de rotina. Não sou médica, nem estou no dia-a-dia da rede pública dos hospitais, mas observo que essa rede tem dificuldades em prestar atendimento hospitalar de qualidade para situações que escapam ao nosso cotidiano. Quando se coloca na rede hospitalar tanto a pública como a privada - alguma atividade extra, ela colapsa. Apresenta diferentes graus de dificuldade para dar respostas à população, um atendimento de qualidade, o que a medicina hoje já oferece. Um exemplo foi o que ocorreu no ano passado, com a epidemia de dengue e, agora, com essa pandemia de influenza. Não é novidade o que estou falando, não falo contra o Ministério da Saúde; faço apenas uma constatação do que acontece na realidade.

Tivemos ano passado uma epidemia de dengue. O problema é: como os hospitais podem dar apoio a isso? Na dengue, a rede hospitalar pode funcionar para os casos graves, de uma forma mais simples do que em uma epidemia de influenza, quando o paciente precisa de respiradouro, ventilação mecânica, uma série de equipamentos. Os casos graves requerem assistência médica diferenciada da de outras epidemias, como as de sarampo e rubéola, 
hoje de menor impacto na população. Aí a rede consegue dar razoável apoio, mas quando é necessário um apoio diferenciado, como agora, a rede apresentam problemas. Durante a pandemia formaram-se enormes filas de espera nas unidades de emergência, tanto públicas como privadas, vários hospitais tiveram dificuldades de abrigar os pacientes e os deslocaram para outros hospitais, que, às vezes, nem estavam preparados para recebê-los.

Houve participação maior dos postos de saúde durante essa epidemia, na triagem e no diagnóstico aos primeiros sintomas. E isso faz diferença, se compararmos com a epidemia de dengue, não?

Marilda M. Siqueira - Foram usadas várias estratégias pelo governo, algumas bastante felizes, principalmente no início da pandemia. Uma delas foi o sistema de contenção, que é tentar conter o espalhamento do vírus e sua transmissão. No início, o governo estava usando - e continua a usar - essa estratégia de maneira bastante intensa, principalmente nos aeroportos, com a vigilância do viajante. Quem vinha de fora e apresentava sintomas respiratórios era monitorado, assim como os contatos dele na empresa, na família, na comunidade, na escola, onde quer que circulasse. A ideia era: quanto mais você postergar a transmissibilidade do vírus, melhor. Dá tempo de todo o sistema se organizar, se preparar. Essa atividade o governo fez com bastante sucesso.

Atrasou de fato a chegada do vírus?

Marilda M. Siqueira - Parece que sim. O que fez a transmissibilidade aumentar muito foi o feriado de corpus Christi, em junho deste ano. Tivemos dois feriados muito próximos, naquela época, e muitos brasileiros foram ao Chile e à Argentina. No laboratório, percebemos isso claramente. Recebíamos amostras de pacientes com sintoma de infecção respiratória aguda, e quando constava, na ficha de investigação do indivíduo, a procedência 'Buenos Aires', até brincávamos: "Este será mais um positivo... ". E era mesmo.

Enfim, foi um marco, um divisor de águas no Brasil. É muito difícil segurar essa transmissibilidade quando há muitos casos de infecção respiratória. O governo se empenhou mesmo para atrasar ao máximo a chegada e a transmissão do vírus.

Há anos os especialistas preveem o ressurgimento de uma gripe tão letal quanto a de 1918. A pandemia atual começou sob a expectativa de que esse vaticínio enfim se realizava, o que não ocorreu. Por que o vírus agora é menos letal? Qual a relação entre a letalidade do vírus e a sua capacidade de transmissão?

Marilda M. Siqueira - São vários motivos. O sistema todo, os países e a Organização Mundial de Saúde (OMS), já se preparavam, mas pensando na gripe aviária, a influenza H5, que tem se apresentado nos países do Sudeste asiático. O vírus está circulando em aves, mas quando consegue ser transmitido para o homem, a letalidade dele é altíssima, mais de $50 \%$. É claro que, num primeiro momento, se havia transmissão de um vírus com potencial pandêmico, a OMS e os países fizeram muito bem em declarar alerta máximo, porque poderia ser um vírus com esse grau de letalidade - não se sabia. Além disso, naqueles primeiros dias, os dados vinham dos Estados Unidos e do México. Este último, naturalmente, 
inspirava uma preocupação muito maior, por ser um país mais parecido com o nosso em termos de recursos. O México apresentou mais de mil casos e admitiu 140 mortes. Ora, mil e tantos casos de uma doença e $10 \%$ ou mais de mortes provocam um impacto muito grande e nos levam até mesmo à pergunta: será só esse o número de mortos?

Depois, analisando os dados que começaram a surgir com a circulação do vírus em outros países, passamos para outro momento, quando se observou que a gripe poderia não causar tanta mortalidade, como as pessoas temiam. E começaram a se fazer comparações: é igual a uma influenza sazonal? Enfim, foi essa a mensagem que se começou a passar para o público.

Acho que ainda temos muito que aprender com essa epidemia. Faltam dados. Um dos países com dados de melhor qualidade é o Chile, por que o sistema de saúde de lá é modelar. Além disso, o vírus ainda está circulando pouco na Europa; só na Inglaterra, por que ainda não é inverno. Vamos analisar países do Terceiro Mundo, para tentar obter conclusões mais realistas para nós. No Chile, dos pacientes que fazem casos graves, 10\% estão morrendo. Não acho que essa pandemia justifique o alarde, mas também não acho que seja algo normal ou tão tranquilo como alguns dizem.

A incidência de casos letais é mais alta do que a registrada com o vírus do nosso último inverno?

Marilda M. Siqueira - Não temos dados. Desta vez estamos trabalhando juntamente com o diagnóstico laboratorial. Os dados que a maioria dos países do Terceiro Mundo tem de influenza sazonal são os que chamamos flu like, ou seja, os com sintomas parecidos com os da gripe: o indivíduo morreu com um quadro respiratório que poderia ser de influenza. Agora, dados concretos, com diagnóstico laboratorial, ainda não há, a investigação está sendo feita agora. A comparação é difícil quando se olha sob esse prisma. Faltam-nos dados para comparar.

O que estamos vendo é que o número de pessoas infectadas é assustadoramente maior do que numa influenza sazonal. Também por ser a primeira vez que entramos em contato com o vírus, há tendência de quadros leves a moderados, mais do que na influenza sazonal, em que a maioria faz quadros leves.

\section{Tem-se um mapeamento melhor dos casos?}

Marilda M. Siqueira - Vários cenários precisam de avaliação mais cuidadosa. Há uma certa ansiedade para obtermos todas as respostas, mas esse vírus está circulando há apenas quatro meses. É muito pouco tempo para concluir sobre tanta coisa: como ele vai comportarse na África, por exemplo? Como vai comportar-se em lugares mais pobres, aqui mesmo no Brasil? Ainda necessitamos de dados precisos, que as secretarias de Saúde trabalhem mais esses dados. Com os hospitais lotados, elas ainda não tiveram tempo para avaliar os resultados desses quatro meses de pandemia; no momento, o foco é outro. A população e mesmo nós, pesquisadores, precisamos ter mais calma. Não dá para saber tudo agora. É preciso estudar mais o vírus, entender melhor como ele se comporta. Temos muitos mais pontos de interrogação do que afirmativas, com certeza. 
Por que as crianças transmitem o vírus da gripe suína por mais tempo do que um adulto? Os grupos de risco também parecem ter mudado: qual a razão disso?

Marilda M. Siqueira - Eu também quero saber por que mudaram; essa é uma das perguntas [risos]. Talvez as crianças transmitam o vírus por mais tempo porque ficam infectadas mais tempo também - não sabemos. Quanto aos mais velhos, as pessoas com mais de sessenta anos são sempre um grupo de risco para influenza, e as campanhas de vacinação destinamse a elas. Três vírus sazonais circulam desde 1976: o influenza B, o influenza A (H3N2) e o influenza A (H1N1). Este é um vírus sazonal também. Por que o vírus não está matando como poderia nesse grupo etário? Talvez por que essas pessoas já tenham entrado em contato com esse vírus há muitos anos, tanto por meios naturais quanto pela vacina. $\mathrm{O}$ vírus atual é diferente, por que os segmentos do genoma do H1N1 sazonal são de vírus humano. O responsável pela atual pandemia é um rearranjo genômico de três vírus de influenza: tem o segmento aviário, o segmento humano e segmentos de vírus suíno. Então não é igual ao vírus sazonal, apesar de ser um vírus H1.

Ele é um rearranjo de três vírus de influenza?

Marilda M. Siqueira - Não de três vírus, mas sim de três espécies diferentes: aviária, humana e suína. Um segmento do genoma é aviário, é um H1 mas não é igual ao sazonal. De qualquer maneira, será que se tem imunidade cruzada entre o vírus sazonal e esse suíno? Será que o anticorpo de um protege, pelo menos um pouquinho, contra outro? Não sei, precisamos de mais estudos sobre isso. Parece que não; se tiver, é muito pouco...

Em geral, as mulheres grávidas são grupo de risco para qualquer infecção, porque têm imunidade mais baixa. Há mais um problema: esse vírus causa infecção respiratória, e a mulher, no último trimestre da gestação, está com o diafragma comprimido pelo feto. Ora, se há uma doença em que a capacidade ventilatória do paciente pode ser um fator importante para agravá-la, imagine quando essa capacidade é restringida pelo próprio diafragma, que está sob compressão. Claro que fica maior a possibilidade de agravamento.

$\mathrm{Na}$ influenza sazonal, os casos de mulheres grávidas também podem complicar. Só que elas já estão em contato com o vírus durante muitos anos. Se a mulher tem vinte anos, teve por 19 vezes a chance de exposição ao vírus - todos os anos temos a possibilidade de entrar em contato com os vírus sazonais -, então tem grande chance de fazer uma influenza mais branda, porque já tem anticorpo. Com o vírus atual não, é a primeira vez. Isso pode ser uma das causas do agravamento dos casos em gestantes: elas entram em contato com o vírus já com a imunidade mais baixa e com a capacidade ventilatória mais reduzida; são suposições ainda em estudo.

Há expectativa de a medicina e a tecnologia médica permitirem, a curto prazo, que se chegue a um antiviral ou uma vacina que neutralize de vez a ameaça representada pelos vírus das gripes? Haverá uma vacina capaz de evitar a infecção pelos vírus da influenza, por mais que se transformem, ou o fato de serem tão mutantes inviabiliza isso? E a vacina aplicada em grupos com mais de sessenta anos: ela poderá ser distribuída a toda a população? 
Marilda M. Siqueira - Isso está muito longe de ocorrer. É muito otimismo achar o contrário, até porque o vírus influenza tem reservatórios animais. Uma coisa é trabalhar num programa de eliminação de sarampo, rubéola e pólio, por exemplo, que não têm reservatórios em animais. Você vacina a população mundial e consegue deter a doença. Erradicamos a pólio e estamos agora eliminando o sarampo e a rubéola das Américas. Já o vírus da influenza tem reservatórios animais, circula na natureza. Vamos fazer o quê? Eliminar todos os animais silvestres? Não tem como. Fazer uma vacina que atinja todos os tipos de vírus influenza? Há muitos estudos contemplando alguns segmentos ou algumas proteínas do vírus e que poderiam dar origem a uma vacina capaz de proteger, pelo menos, a maioria das espécies. Mas a questão é que, normalmente, a imunidade induzida pelo vírus influenza não é muito longa. Essa é a razão por que temos de tomar a vacina todos os anos: não só porque o vírus muda, mas também porque, depois de certo tempo de você ter tomado a vacina, os anticorpos diminuem muito. Pensar em uma vacina para todos os tipos de vírus de influenza me parece uma meta inatingível a médio prazo.

Só no ano passado, a gripe comum matou cerca de setenta mil pessoas no país, mas ela deverá perder força em razão do surgimento da nova doença - a afirmação, veiculada na Folha de S. Paulo online de 6 de agosto de 2009, é do infectologista e professor da Universidade Federal de Minas Gerais, Unaí Tupinambás, que lida com doenças infectocontagiosas. Segundo ele, a tendência é que a incidência do vírus (A H1N1) aumente no Brasil, a ponto de a gripe suína poder se tornar a gripe sazonal do próximo ano. É isso mesmo?

Marilda M. Siqueira - É basicamente isso. Ele ainda não é vírus sazonal, ainda é pandêmico, mas ano que vem pode se transformar no vírus sazonal. Na história do vírus influenza é isso que acontece: quando um novo vírus pandêmico é introduzido na população, em cerca de um ano, dependendo do país, ele toma o lugar de sazonal; é a história natural da virologia. Temos de esperar o ano que vem para ter ideia do que vai circular. No Nordeste do Brasil, a proporção do sazonal para pandêmico ainda não chegou a 45\%, porque a infecção se alastrou mais no Sul e no Sudeste. Daqui a um tempo eles vão ter o padrão que nós temos agora. Não posso precisar a proporção.

Aí então a população sofrerá menos, será menor a ocorrência de casos graves?

Marilda M. Siqueira - Não sabemos a porcentagem da população infectada, porque há os assintomáticos. Teoricamente, estamos estudando casos graves. Recebemos muitos não tão graves, mas deveríamos dar atenção apenas aos casos graves que foram notificados até agora.

Como será a distribuição da vacina produzida pelo Instituto Butantan? Há uma estratégia ou critérios, como vacinar primeiro grávidas e crianças, que fazem parte de grupos de risco? Que percentual da população será coberta por esta proteção?

Marilda M. Siqueira - Isso ainda não está definido. A fase agora é de planejamento, de estudar como será a distribuição da vacina. Existia uma estratégia baseada na imunização 
da população acima de sessenta anos, mas o fato de, nessa pandemia, o vírus atingir com maior gravidade crianças e grávidas exige que as estratégias de vacinação sejam reavaliadas. O número de imunizados dependerá também do estoque disponível de vacinas.

Pesquisadores americanos e europeus contemporâneos estudam o vírus da gripe de 1918. Essas iniciativas trazem alguma contribuição para o conhecimento da doença atual?

Marilda M. Siqueira - Esses estudos foram muito interessantes para entendermos a evolução do vírus. Em 2007 foi publicado, nos Estados Unidos, um artigo demonstrando a evolução do vírus de 1918 até então. Porém é muito difícil comparar 1918 com a pandemia de 2009. O mundo é muito diferente. Em 1918 a Europa saía de uma guerra mundial, a fome atingia populações inteiras, não existia antibiótico - a penicilina só foi descoberta na década de 1930. Hoje, três dias depois de identificado o novo vírus, a OMS foi notificada pelo CDC, o Centro de Controle de Doenças do EUA, e começamos a acompanhar sua trajetória e evolução.

Existe alguma evidência científica de que o vírus A (H1N1) possa apresentar resistência ao antiviral Oseltamivir? Seria este um dos motivos da não distribuição mais generosa do medicamento? Em parte da América, a distribuição visa atingir rapidamente os possíveis infectados. No Brasil, a distribuição é feita somente para aqueles com confirmação laboratorial da doença. Essa diferença teve algum efeito prático?

Marilda M. Siqueira - Existem, no mundo, sete casos conhecidos de resistência ao Osetalmivir. Por quê? Ainda é cedo para responder a essa pergunta. Estamos acompanhando os casos, a evolução e a disseminação do vírus. Ele já chegou ao Sudeste asiático, e não sabemos como vai comportar-se por lá. E se encontrar com o H5, o que pode resultar disso? Um novo rearranjo? E aí, o que vai acontecer? E quando começar a infectar na África?

Os casos precisam ser acompanhados, e o Oseltamivir precisa ser dado. É o que temos para combater as infecções respiratórias. Em saúde pública, damos para o filho dos outros o que daríamos para os nossos. Cada país distribui o remédio conforme sua capacidade de estoque, de planejamento e organização.

Poderia fazer uma apreciação sobre as campanhas de vacinação ocorridas em outros períodos de gripe? Houve efeitos colaterais graves?

Marilda M. Siqueira - Em 1976, se não me engano, houve problemas com uma vacina contra a gripe nos Estados Unidos,. Os efeitos colaterais foram muitos. O problema é que os governos precisam saber escolher os laboratórios com os quais vão trabalhar. A indústria farmacêutica não tem por objetivo errar. E há formas de controlar isso, há protocolos, testes que o Instituto Nacional de Controle de Qualidade em Saúde (INCQS), da Fiocruz, aplica a toda hora com produtos fabricados no Brasil. 